\title{
O presente como problema historiográfico na Primeira República em dois manuais escolares
}

The present as a historiographical issue at the First Republic in two school textbooks

Marcelo de Souza Magalhães*

Rebeca Gontijo ${ }^{\star *}$

\section{RESUMo}

$\mathrm{O}$ artigo busca analisar alguns usos do presente e seus desafios no que diz respeito ao ensino escolar da história. Nesse sentido, focaliza um período no qual a experiência dos homens em seu próprio tempo foi abalada por incertezas quanto ao futuro e ao passado: a primeira década da República no Brasil (18891899). Supostamente, naquele momento o presente assumiu um lugar importante nas narrativas da história destinadas ao uso escolar, ainda que impondo muitas dificuldades a seus autores.

Palavras-chave: Primeira República; manuais escolares; história do tempo presente.

\section{Abstract}

The article intents to analyze some uses of the present and its challenges regarding history school teaching. Thus, it focuses in a period in which men's experience of their own time have been shaken by uncertainties about both future and past: the first decade of the Brazilian Republic (1889-1899). Supposedly, at that time, the present had taken an important place in history narratives devoted to schools, even though it placed a heavy burden upon its authors.

Keywords: First Republic; school textbooks; history of the present time.

Sujeito às impressões do momento, às paixões, às simpatias e às antipatias, ou seja, sendo ator no drama de que procura dar conta, aquele que escreve sobre a história contemporânea do seu país escreve um pouco a sua própria história.

Joaquim Manoel de Macedo RIHGB, tomo XXVI, 1863, p.854

\footnotetext{
* Universidade Federal do Estado do Rio de Janeiro (UniRio).marcelosmagalhaes@hotmail.com

** Universidade Federal Rural do Rio de Janeiro (UFRRJ).rebeca.gontijo@gmail.com
} 
Não passei além da proclamação da república (1889); os sucessos são ainda do dia de hoje e seria prematuro julgá-los em livro destinado ao esquecimento das paixões do presente e à glorificação da nossa história.

João Ribeiro História do Brasil - Curso Superior, 1900

Pode causar estranheza ao leitor uma discussão historiográfica sobre o tempo presente na Primeira República. Isso porque a expressão história do tempo presente adquiriu legitimidade entre os historiadores profissionais mais recentemente, a partir dos anos 1970, como parte de um processo iniciado após a experiência da Segunda Guerra Mundial (1939-1945) e a difusão de testemunhos dos sobreviventes. Desde então, observa-se um crescente interesse da historiografia por acontecimentos ocorridos em período próximo, especialmente os traumáticos, impondo a necessidade de interrogar e confrontar testemunhos vivos. ${ }^{1}$

Contudo, cabe observar que embora a expressão história do tempo presente seja recente, a preocupação com ela é muito antiga, se considerarmos que desde Heródoto e Tucídides (século V a.C.) havia projetos de escrita da história do presente. ${ }^{2}$ Mesmo no século XIX, quando a história é definida como conhecimento do passado, é possível localizar reflexões e projetos de escrita da história do presente, embora a maioria deles tenha fracassado. ${ }^{3}$

Este artigo pretende analisar alguns usos do presente ${ }^{4}$ e seus desafios no que diz respeito ao ensino escolar da história. Nesse sentido, propomos focalizar um período no qual a experiência dos homens em seu próprio tempo foi abalada por incertezas quanto ao futuro e ao passado: a primeira década da República no Brasil (1889-1899). Naquele momento o presente assumiu um lugar importante nas narrativas da história destinadas ao uso escolar, ainda que impondo muitas dificuldades a seus autores. Compreendemos que os homens de letras do período buscaram formas para lidar com as questões colocadas pelo presente, por vezes caindo em contradições - visto que o estudo do contemporâneo era identificado como um risco a ser evitado - mas, ao mesmo tempo, parecia impor-se diante das incertezas quanto ao futuro e da dúvida quanto ao papel do passado. A transformação da experiência modificando a relação entre passado, presente e futuro e, por conseguinte, interferindo na escrita e no ensino da história. 
Francisco Gouvêa analisa a comemoração dos 50 anos do Instituto Histórico e Geográfico Brasileiro (IHGB), em 1888, quando é possível observar o empenho dos sócios no sentido de avaliar a história do IHGB e sua relação com a da própria nação, manifestando a expectativa de continuidade da monarquia constitucional em um terceiro reinado. Ao menos para os membros do grêmio, até a proclamação o futuro era lido como continuidade de um presente: o Império. A análise de Gouvêa acompanha a frustração dessa expectativa pela proclamação da República no ano seguinte, observando-se que, num primeiro momento, prevalece certa postura de afastamento em relação aos acontecimentos. A queda do Império é sentida como uma perda, e a República é vista como uma revolta. Num segundo momento, a República passa a ser identificada como proclamação, remetendo à ideia de consentimento, tal como observada por Maria Tereza Chaves de Mello. Essa autora investiga a difusão de uma cultura democrática e científica no final do Império (anos 1870 e 1880), argumentando que contribuiu para a criação de uma "disponibilidade mental e afetiva” à ideia de República no Brasil, por oposição ao Império. A oposição desses termos, observada em variados discursos, permitiu aos contemporâneos experimentar o processo histórico mediante o estabelecimento de uma relação de oposição entre o passado (associado ao Império e ao atraso) e o futuro (relacionado à República, ao progresso e à modernidade) (ver Mello, 2009; 2007). A partir de então, observa-se o empenho em restabelecer a relação entre passado, presente e futuro até que as raízes da República são fincadas no passado colonial e na história da América, a monarquia passando a ser vista como um interregno. O sentido da história demarcando a inevitabilidade do novo regime. ${ }^{5}$

Acreditamos que os manuais escolares contribuíram para a construção desse sentido, na medida em que representaram um esforço concentrado para ordenar o tempo e sintetizar a história, atribuindo-lhe sentido e difundindo pontos de vista capazes de penetrar no universo escolar e formar novos cidadãos. Diante da incerteza quanto ao futuro que marcou o início da República, tanto para republicanos como para monarquistas, observamos o empenho para rearticular passado, presente e futuro de modo a transformar o presente (a República recém-proclamada) em passado rapidamente, permitindo que a história recuperasse seu sentido. Cabe ainda observar que essa rearticulação do tempo não se fez sem disputas, e que a escrita da história a ser ensinada foi 
produzida ao mesmo tempo em que vigorava a expectativa por uma nova história geral do Brasil. ${ }^{6}$

Mas como foi possível reescrever a história a ser ensinada nos anos iniciais da República? Em primeiro lugar, a pretensão à verdade e a busca de "critério, boa fé e imparcialidade" eram vistas como fundamentais para a escrita da história desde o século XIX. E se a fundação do Instituto Histórico e Geográfico Brasileiro (IHGB), em 1838, ilustra a preocupação da elite letrada com relação ao futuro e ao presente da nação, foi a percepção da falta de um passado comum, capaz de integrar as partes ao todo, que incentivou a busca de fontes e a escrita da história nacional. Projeto político e historiográfico que atribuiu um papel importante ao historiador e ao ensino escolar da história, este último destinado a formar súditos para o Império. ${ }^{7}$

No início da República, a relação entre presente e passado novamente se impôs aos intérpretes que buscavam encontrar no segundo a possibilidade de legitimar as ações e acontecimentos do primeiro - no caso, tratava-se de legitimar o novo regime político. ${ }^{8}$ Considerando a tradição historiográfica oitocentista, cabe indagar: como os homens de letras que se dedicavam à escrita da história procuraram lidar com os problemas do presente relacionados à República? Quais os limites e possibilidades da historiografia, incluindo aquela destinada ao uso escolar, diante dos acontecimentos contemporâneos e da experiência do tempo em transformação?

Para responder a tais questões no limite deste artigo, propomos o seguinte exercício: apresentar dois escritos destinados ao uso escolar produzidos nas primeiras décadas republicanas, procurando observar as possibilidades e limites da abordagem do tempo presente.

\section{Atualizar, REVER, AMPLIAR}

Antonio Augusto Gomes Batista chamou atenção para a efemeridade da literatura didática, considerando seu constante processo de revisão e atualização, devido, por exemplo, à mudança nos programas oficiais de ensino (Batista, 1999). Por isso, talvez, a impressão de que os livros didáticos são obras abertas, pois estão sujeitos a constantes ampliações e modificações de conteúdo.

Ao mesmo tempo, observamos que, embora a literatura didática esteja sempre aberta à revisão de conteúdo, a perspectiva que a orienta pode 
permanecer por longo tempo. Apesar dessa contradição inerente aos materiais didáticos, é possível pensar que eles podem ser, simultaneamente, efêmeros, por terem que, de alguma forma, passar por uma atualização constante dos conteúdos, incorporando o tempo presente, próximo às experiências vividas pelos alunos; e permanentes, pois o ponto de vista historiográfico que os orienta pode se manter por longo tempo, por vezes ignorando outros pontos de vista, que servem de base para a renovação da própria historiografia. ${ }^{9}$

Uma questão aqui colocada é saber como a ampliação dos conteúdos até o presente pode impor aos autores de manuais escolares de história a necessidade de lidar com fatos de seu próprio tempo, o que, inevitavelmente, estabelece um problema epistemológico e, também, político, que não é necessariamente enfrentado, mas por vezes é colocado. Essa colocação pode ser observada quando o autor do livro manifesta sua preocupação nas notas de advertência ou prefácios, a exemplo do texto de João Ribeiro citado na epígrafe. A abordagem do presente, naquele momento, deparava com a exigência de imparcialidade que, por sua vez, estabelecia a distância temporal dos fatos abordados como algo necessário.

Nesse sentido, o estabelecimento da cronologia parece ser um procedimento fundamental, considerando que por meio de quadros cronológicos ou periodizações é possível apreender o tempo, ordená-lo de modo a atribuir-lhe um sentido, uma direção. O estabelecimento dos fatos e sua apresentação por meio da narrativa didática também constituem uma forma de ordenar o tempo na medida em que tais fatos aparecem interligados em uma sequência supostamente capaz de explicar o rumo dos acontecimentos, às vezes apontando causas e efeitos, além dos marcos fundamentais.

Contudo, não era tarefa fácil selecionar os fatos. No século XIX, a escolha dos acontecimentos do presente a registrar podia ser vista como um ato capaz de levar à produção de uma obra imperfeita, porque submetida ao juízo de valor daquele que seleciona e exclui os fatos da história. No parecer sobre a proposta de Felizardo Pinheiro de Campos para a escrita de um livro sobre os Fastos do feliz e glorioso reinado do Sr. Dom Pedro II, emitido por Joaquim Manuel de Macedo em 1863, observa-se essa preocupação com a seleção dos fatos e o problema político implicado nessa escolha. Macedo considerava que a seleção implicava a emissão de um juízo, uma "apreciação dos fatos a registrar". A escolha e a exclusão gerando um "grave inconveniente" e um resultado 
que o parecerista considerava evidente: a produção de uma obra incompleta em razão de possíveis esquecimentos (ver Tiburski, 2011, p.91-92).

Ao longo do Oitocentos, a discussão sobre a cronologia atravessou tanto a historiografia como o ensino escolar da história, cuja estruturação curricular exigia a definição de períodos e a ordenação dos fatos considerando o Estado nacional como sujeito principal, e a tarefa não favorecia consensos (ver Rodrigues, 1978; Cezar, 2004a, p.17; Bittencourt, 1992-1993). O problema colocado no início da República representa um desafio porque, embora a abordagem do presente fosse problemática pelos motivos apontados anteriormente, continuava sendo necessária diante da urgência de ordenação do tempo, se considerarmos que tal procedimento permitiu transformar o presente e seus agentes em passado rapidamente. Permitia, por conseguinte, transformar a República em objeto de estudo histórico e, também, em tema ensinável. Restaria ainda definir os documentos e testemunhos capazes de permitir sua efetiva historicização.

\section{DA FASE DOCUMENTAL À SÍNTESE DIDÁTICA}

\section{Ao leitor}

É cedo ainda para fazer a história; tempo já é, porém, de coligir documentos e informações, hauridas estas na fonte viva e pura, colhidos aqueles nas publicações recentes, feitas a desafio das testemunhas presenciais.

Tal a razão de ser d'este folheto, ao qual certamente hão de outros suceder.

Somenos é hoje seu valor, mas assim não será amanhã; e, com o profundar dos tempos, de aumento irá seu valor, porque ele relata com fidelidade, pouco comenta e sem paixão, tudo diz sem interesse de agradar nem temor de desagradar.

$O$ autor d'este folheto não o concebeu para fazer oblata a quem quer que seja, sim somente para satisfazer à verdade histórica.

Joaquim José de Carvalho Primeiras linhas da história da república dos Estados Unidos do Brazil, 1889, p.4

O folheto de Joaquim José de Carvalho publicado em 1889 é apenas um exemplo do tipo de material posto em circulação logo após a proclamação da 
República. O autor estabelece como objetivo imediato: reunir documentos e informações na "fonte viva e pura", visando atender à "verdade histórica".

Como observou Angela de Castro Gomes, é grande o número de títulos publicados nas primeiras décadas da República. Esse conjunto de textos oferece interpretações sobre o tempo presente, um período próximo no qual o intérprete está inserido e cujo conteúdo é marcado pela presença de atores vivos, resultando em uma "história que ainda está viva". Ao mesmo tempo, essa é também uma história imediata, marcada pela produção de relatos e memórias de vários tipos elaborados "no calor da hora dos eventos" (Gomes, 2011, p.55).

Nas palavras de Castro Gomes, era

uma história do presente, que fabricava um passado para si mesma e que se debruçava, como não podia deixar de ser, sobre os fatos cruciais recém-acontecidos: o fim da monarquia (que incluía menções à abolição da escravidão); os propagandistas e a propaganda republicana; e a jornada do 15 de novembro, com seus novos heróis da pátria. (ibidem, p.58)

Ainda segundo a autora, um levantamento realizado por Silvio Peixoto nos anos 1950 expõe o tipo de contribuição identificada nesses livros, menos relacionada à análise que seus autores - muitos dos quais eram atores e/ou testemunhas dos eventos sobre os quais escreviam - faziam dos eventos, do que à oferta de informações, as provas documentais que, de modo particular, contavam os acontecimentos, constituindo a República enquanto uma evidência histórica. E, além da oferta de documentos, cabe destacar a presença de biografias, memórias e alguns ensaios e estudos que privilegiavam a interpretação dos fatos ou, como observou Gomes, a oferta de uma opinião do autor sobre os acontecimentos. Em todas essas produções evidencia-se o compromisso com a verdade e a preocupação em desvendar e evitar seu falseamento pelas paixões (ibidem, p.59).

Chama atenção o fato de que esses primeiros textos sobre a República no Brasil, além de oferecer interpretações, ocupam-se de apresentar documentos diversos, tais como notícias de jornais, gravuras e decretos. Compreendemos que esses materiais serviam ao propósito de buscar no passado as 'origens' da República, tema fundamental das reflexões sobre o novo regime político no fim do século XIX. 
Dito isso, analisaremos, a seguir, a recepção da República dada a ler nos manuais escolares escritos por Felisbello Freire e João Ribeiro, os quais construíram narrativas históricas entre 1896 e 1900.

Felisbello Firmino de Oliveira Freire (1858-1916) formou-se pela Faculdade de Medicina da Bahia (1882), e no início da República ocupou cargos públicos de destaque. Foi o primeiro presidente do estado de Sergipe (1889-1890), sua terra natal. Foi ministro das Relações Exteriores e da Fazenda na década de 1890 e sócio do Instituto Histórico e Geográfico Brasileiro (IHGB). Escreveu livros como: História de Sergipe (1891), História constitucional da República dos Estados Unidos do Brasil (1894) e História do Banco do Brasil (1907).

O livro História do Brasil, cuja primeira edição é de 1896, sete anos após a instauração da República, foi escrito para ser adotado nas escolas primárias. Composto por 25 capítulos, pelo índice é possível perceber os personagens históricos considerados principais: Cristóvão Colombo, Américo Vespúcio, Mem de Sá, Maurício de Nassau, Pedro I, Pedro II, Caxias, Osório e Tiradentes, dentre outros.

Os capítulos dividem-se em temáticas que circulam em torno dos descobrimentos, da constituição político-administrativa (governo geral, capitanias hereditárias etc.) e das batalhas internas e externas (invasões, expulsões, insurreições e guerras). A história narrada por Freire tem como enfoque a esfera do político, em que 'grandes' personagens e a ação do Estado são protagonistas.

As histórias escritas no início da República atribuem novos sentidos a personagens e a acontecimentos presentes nos textos historiográficos desde o Império. Por exemplo, Conspiração de Tiradentes, os incondifentes é o título do capítulo sobre o movimento ocorrido em Minas Gerais do século XVIII. Pelo título, fica evidente o protagonismo de Tiradentes. O personagem, que não tinha espaço de destaque nas narrativas históricas do Império, ganha outro lugar na República e mesmo antes, para envolvidos no movimento abolicionista e na propaganda republicana. ${ }^{10}$

Os capítulos, organizados de forma cronológica, pela disposição do que vem antes e depois, ajudam a relacionar acontecimentos diversos no tempo e no espaço. 
Os capítulos antes do término da história, ou melhor, daquela história, são: Guerra do Paraguai, Caxias e Osório, A emancipação dos escravos e Proclamação da República.

A “emancipação dos escravos" e a "Proclamação da República”, eventos relacionados pelo autor, constituem o tempo presente abordado por Felisbello Freire no livro escolar. A escravidão é tratada como uma instituição secular, instaurada pelo fato da necessidade de homens para trabalhar na lavoura. Procura-se explicar a opção pelos africanos, afirmando que eram mais adequados, por conseguirem aguentar o clima tropical e os excessos da escravidão. Fora isso, a opção deveu-se ao fato de que os índios foram defendidos pelos jesuítas. Em seguida, faz-se referência a medidas legais - 26 de novembro de 1826, acordo feito com a Inglaterra para extinguir o tráfico; 4 de setembro de 1850, lei Euzébio de Queiroz, que extingue o tráfico de fato; 28 de setembro de 1871, lei do ventre livre - e a propaganda abolicionista no parlamento, nas ruas e na imprensa. O capítulo termina com este trecho:

$\mathrm{O}$ trono não querendo romper sua aliança com a classe agrícola, fez o programa de resistência com a organização do ministério de 20 de agosto de 1886, sob a presidência do barão de Cotegipe que melhor do que ninguém cumpriu seu programa com muito talento e sinceridade. Quanto mais a opinião oficial resistia mais a opinião pública reclamava e avolumava-se a propaganda, até que o trono capitulou apresentando o ministério de 10 de março de 1888 o projeto de abolição da escravidão que a 13 do mesmo mês [sic] era lei do país. (Freire, 1896, p.150-151)

No capítulo, não há menção à princesa Isabel. A força da opinião pública e da propaganda abolicionista é que vencem o trono, obrigando o governo e o Parlamento a abolirem a escravidão. Logo, o fim da escravidão foi uma vitória da sociedade, representada no trecho pela opinião pública.

Freire inicia o capítulo sobre a proclamação da República, já assim denominado, afirmando ser o manifesto republicano de 1870 um marco da segunda fase da propaganda republicana, sendo a primeira a propaganda abolicionista. O autor observa que o manifesto foi publicado logo após a Guerra do Paraguai,

\footnotetext{
${ }^{1}$ Registre-se que Felisbello Freire cometeu um equívoco com relação ao mês da abolição da escravidão, ocorrida em maio de 1888.
} 
o que, de alguma forma, relaciona os dois eventos: a experiência militar na guerra e o movimento republicano. Fora isso, abolicionismo e republicanismo estão relacionados por constituírem as duas faces de uma mesma moeda: a propaganda em defesa da instauração da República no Brasil.

No livro, foram identificados dois fatores que levaram ao 15 de novembro, ou melhor, à proclamação. A abolição da escravidão é o primeiro fator. A propaganda abolicionista é compreendida como uma manifestação da propaganda republicana. Propaganda que seguiu dois caminhos: o da emancipação dos escravos e o da emancipação dos cidadãos. Os atritos do Exército com a autoridade civil são identificados como o segundo fator. Freire afirma ter existido um programa de perseguição feita aos membros do Exército, transferindo alguns de seus membros para lugares distantes, no interior do Brasil. Além desses fatores, também há menção ao desprestígio do Império no final da década de 1880 .

Mesmo próximo da instauração do novo regime, o livro mobiliza determinados elementos que serão recorrentemente utilizados em narrativas históricas posteriores, como fatores explicativos para o fim do Império. Há menções ao desprestígio do regime monárquico ao final da década de 1880: excessos cometidos pelos partidos (acusados de governarem com violência e ambição), decadência e miséria das províncias (como consequência da centralização monárquica), libertação dos escravos, questões militares, doença do imperador e perspectiva baixa da existência de um Terceiro Reinado. "Tudo isto dava uma feição especial à situação política do país, indicando uma completa transformação na economia nacional, que fatalmente determinava a queda da monarquia" (ibidem, p.153).

A República é identificada como a "revolução democrática" do país, e seus personagens principais são Deodoro da Fonseca - "braço da revolução" - e Benjamin Constant - "grande propagandista da República na classe militar”. A narrativa dos acontecimentos do 15 de novembro contrasta a revolta dos militares motivada pela possibilidade de transferência para o interior do Brasil e o último baile do Império, o da Ilha Fiscal. $\mathrm{O}$ autor chega a identificar o baile como uma verdadeira Versalhes, ou seja, as lideranças do Império aparentam pairar no ar, descoladas das insatisfações diversas, particularmente dos militares. 
João Ribeiro (1860-1934) - professor, jornalista, historiador, crítico e filólogo - à época da publicação de seus livros pertencia aos quadros do Ginásio Nacional, novo nome do antigo Colégio Pedro $\mathrm{II}^{11}$ - ocupando a cadeira de História da Civilização e História do Brasil e, posteriormente, de História Universal - e da Academia Brasileira de Letras (ABL). Em 1915, entrou para o Instituto Histórico e Geográfico Brasileiro (IHGB). O autor, ao longo de sua carreira no Ginásio Nacional, escreveu diversos livros escolares: História Antiga (1892); História do Brasil, Curso Primário (1900); História do Brasil, Curso Médio (1900); História do Brasil, Curso Superior (1900); História Universal (1918) e História da Civilização (1932). Além desses livros, publicou gramáticas da língua portuguesa. Os seus escritos, em grande parte, foram publicados por Francisco Alves, editor que, na primeira década republicana, ocupava lugar de destaque no mercado editorial de livros escolares (Hallewel, 1985).

A primeira edição do livro História do Brasil, Curso Superior foi publicada em 1900, ano em que se comemorou o Quarto Centenário do Descobrimento do Brasil. A segunda edição foi publicada no ano seguinte (Ribeiro, 1901). Composta por 399 páginas, a edição de 1901 apresenta um pequeno formato, de $12 \mathrm{~cm}$ de largura por $17 \mathrm{~cm}$ de altura. Além dos capítulos, o livro inclui: um prólogo de Tristão de Alencar Araripe Júnior, intitulado “João Ribeiro. Filólogo e historiador"; a introdução escrita para a primeira edição, intitulada "Do Auctor"; uma sinopse cronológica e uma bibliografia. Diferentemente da edição dedicada às escolas primárias, a edição História do Brasil, Curso Superior não apresenta imagens.

Ribeiro organiza o livro em nove partes, sendo estas divididas em vários capítulos. O índice geral é composto por: I. O descobrimento (11 capítulos); II. Tentativa de unidade e organização da defesa (6 capítulos); III. Luta pelo comércio livre contra o monopólio (11 capítulos); IV. A formação do Brasil. A) A história comum (14 capítulos); V. A formação do Brasil. B) A história local (2 capítulos); VI. Definição territorial do país (2 capítulos); VII. O Espírito de autonomia (4 capítulos); VIII. O Absolutismo e a revolução - República e constituição (4 capítulos); IX. O Império. Progressos da democracia (8 capítulos). Ao todo, são 62 capítulos.

Tanto pelo título geral como pelos das partes que o compõem, percebe-se o grau de inovação presente no livro, afirmado por Ribeiro em sua própria introdução. Ao optar pelo título de História do Brasil, o autor procurou 
diferenciar-se dos dois manuais didáticos adotados no Colégio Pedro II que o antecederam, ambos intitulados Lições de História do Brasil, de Joaquim Manoel de Macedo (1861) e de Luiz de Queiroz Mattoso Maia (c.1880). Como o próprio título indica, o conteúdo desses manuais era distribuído em 'lições', cuja extensão variava de acordo com a importância atribuída ao assunto por seus autores. No caso, ambos privilegiavam os temas políticos e administrativos, ordenados linearmente (Hansen, 2000, p.68).

O fato de o livro de Ribeiro não se organizar em 'lições', mas sim em divisões e subdivisões - que identificamos como partes e capítulos -, já aponta para uma diferenciação em relação aos anteriores. Apesar de alguns capítulos se aproximarem das antigas lições, é possível concordar com a observação de Patrícia Hansen, para quem, no conjunto, tais partes possuíam um sentido próprio. Numa breve análise do índice, logo chamam atenção as partes IV e V, ambas intituladas "A formação do Brasil”, com subtítulos diferentes: “A história comum" e "A história local”, respectivamente. Tais partes ocupam 128 das 399 páginas do livro, quase um terço do total. A República aparece no oitavo capítulo da última parte, intitulada, mais uma vez, "O Império. Progressos da democracia”. Antes dela, sete capítulos: "A Independência”; "A Constituinte"; "A abdicação"; "Sete de abril. Evaristo da Veiga"; "A regência”; "O segundo reinado"; e, por fim, "A guerra do Paraguai”. A instauração do novo regime é tratada junto ao tema da emancipação dos escravos, sendo o capítulo intitulado "A abolição e a república". Na verdade, o capítulo trata quase que exclusivamente do processo que terminou na abolição da escravidão no Brasil. ${ }^{12}$

Com o foco na abolição, o capítulo inicia afirmando que D. Pedro II sempre pregou para seus ministros a necessidade de tomar medidas que visassem emancipar os escravos. Tal interpretação se diferencia da de Felisbello Freire, que atribui ao imperador e ao Parlamento o mesmo papel frente à abolição da escravidão, o papel de resistência. A política adotada pelo imperador, de acordo com Ribeiro, foi a de emancipação gradual, exemplificada pela Lei do Ventre Livre, de 1871. Lei que, com o tempo, acabaria com a escravidão. Porém, Ribeiro lembra que, apesar da lei de 1871, 'exaltados' continuaram com a campanha pela abolição, por meio da criação de partidos abolicionistas. Tal campanha surtiu efeito em 1888, quando a princesa Isabel aboliu a escravidão no Brasil. Outra diferença no que tange à narrativa histórica presente em Freire 
é a menção à princesa Isabel. Apesar da menção, ambos concordam que o fim da escravidão foi fruto, em grande parte, da propaganda abolicionista, ou seja, da mobilização de setores da sociedade.

Para João Ribeiro, a abolição, assinada por Isabel, colaborou para a queda do regime monárquico, pois os senhores de terra que apoiavam o regime ficaram descontentes. Com isso, muitos passaram para o partido republicano e outros ficaram indiferentes aos ataques às instituições monárquicas. Senhores descontentes, membros do Exército e a imprensa republicana aprofundaram a crise política e derrubaram o regime. ${ }^{13} \mathrm{O}$ autor dedica apenas quatro parágrafos ao regime que se instaurava:

A República, era já ... uma aspiração antiga do povo genuinamente nacional. Ao passo que a monarquia era uma transação e o triunfo moral da conciliação entre portugueses e brasileiros, a república, que seria o triunfo exclusivo dos nativistas, já no segundo reinado podia ser uma aspiração política universal, menos partidarista e sem a eiva que caracterizava, em tempos passados, os seus primórdios. A monarquia havia feito baquear o regime colonial e contribuíra assim para dissipar o velho e estreito antagonismo.

Entretanto ainda os eixos amortecidos da mesquinha tradição, uma ou outra vez se avigoraram aos primeiros passos do novo regime, mas baldou-os o desprezo da opinião.

Toda a América era republicana e a exceção que era a monarquia não se justificava por nenhuma excelência.

Na sua história mais recente, a aspiração democrática renasce com a fundação do Clube Republicano e a criação do órgão A República (1871), onde se reúnem vários elementos liberais da política monárquica. A abolição (1888) é o último golpe. Não fossem, porém, as origens militares da república, a paz do primeiro momento seria talvez perturbada, mas seria incomparavelmente maior e mais sólida a simpatia imediata da opinião. (Ribeiro, 1901, p.386)

O tema da República aparece inserido no processo que levou ao fim o império. Logo, não é por acaso que os parágrafos finais da última parte do livro, intitulada "O Império. Progressos da democracia", foram dedicados ao novo regime. Ribeiro claramente associou a República à democracia. Associação que, como demonstra o trabalho de Maria Tereza Chaves de Mello, foi construída nas ruas e tomou o Parlamento, na década de 1880. Além disso, a monarquia era vista, por vezes, como um interregno, período de transição. 
Como fez questão de lembrar Ribeiro, "a América era republicana e a exceção que era a monarquia não se justificava por nenhuma excelência”. Aqui, o autor, como outros homens de letras republicanos, inverte um argumento muito utilizado pelos monarquistas para justificar o regime. A exceção no continente americano era vista como positiva por monarquistas, pelo fato de o regime ter possibilitado a unidade nacional no lugar do risco da fragmentação pós-independência, experiência verificada nas ex-colônias espanholas na América. Os homens de letras republicanos, não necessariamente de forma organizada, inverteram o argumento e fizeram ainda mais, ressaltando que o regime republicano possuía raízes profundas no continente americano. A trajetória da República no Brasil foi a de deixar de ser uma bandeira apenas nativista para passar a ser compartilhada por todos, "uma aspiração política universal”.

Mas, se em História do Brasil, Curso Superior João Ribeiro apresentou algumas restrições à abordagem da República, o mesmo não aconteceu em seu livro dedicado ao ensino primário. O presente passou a ser enfrentado de forma mais direta. Vejamos como o livro didático voltado para as escolas primárias tratou do tema.

História do Brasil. Edição das escolas primárias, publicado pela Livraria Francisco Alves em 1900, em segunda edição, possui, em suas primeiras páginas, uma breve Advertência em que João Ribeiro explica o fato de separar em duas edições seu livro original, uma voltada para a infância e outra para os cursos superiores, dentre estes as escolas secundária e normal. $\mathrm{O}$ autor atribui ao "conselho de vários professores" a decisão pela separação das edições. Coube ao livro voltado para as escolas primárias, sem grandes modificações, o texto apresentado em tipo maior na primeira edição. Também diz que apenas corrigiu erros de impressão e acrescentou algumas pequenas informações. Apesar de ser dedicado à infância, afirma não ter feito uso de uma linguagem infantil, mas ter procurado ser claro, sem "afetação pedagógica".

O livro é composto por 23 capítulos, uma introdução e uma cronologia. Os últimos três capítulos são dedicados ao período do Segundo Reinado: "XXI. Tempos do segundo Imperador (D. Pedro II)", "XXII. A guerra do Paraguai" e "XXIII. A república". Destes capítulos, coube àquele dedicado à guerra do Paraguai o maior número de páginas: nove, restando duas páginas para o capítulo anterior e duas para o dedicado à República. 
Além do texto, o livro possui o total de 16 gravuras, quatro delas dedicadas ao período do Segundo Reinado: D. Pedro II (gravura no 12); Duque de Caxias (gravura $n^{\circ} 13$ ); General Osório (gravura $n^{\circ} 14$ ); Marechal Deodoro da Fonseca (gravura $\mathrm{n}^{\circ} 15$ ). Junto a tais personagens, aparecem outros estampados no livro, dentre eles: Pedro Álvares Cabral, Maurício de Nassau, Henrique Dias, Padre Antônio Vieira, José Bonifácio e D. Pedro I.

O autor, na legenda da gravura de Deodoro da Fonseca, atribui-lhe o epíteto de "fundador da República”. É digno de nota que Deodoro foi o único personagem do período republicano estampado no livro, o que sinaliza para o fato de que o limite para lidar com o tempo presente, no caso do livro de Ribeiro, foi o da instauração da República. Mesmo assim, apesar de vários personagens envolvidos nesse processo, o único que recebeu o status de aparecer em imagem foi o seu 'fundador'.

$\mathrm{Na}$ Cronologia, que possui 53 referências a acontecimentos, nos interessa ressaltar as últimas treze, todas relacionadas ao Segundo Reinado em diante: 1840 - "Maioridade de D. Pedro II"; 1851 - "Guerra de Rosas”; 1865 - “Guerra do Paraguai (1865-1870)"; 1871 - "Lei de 28 de setembro (V. do Rio Branco)"; 1888 - "13 de maio. A abolição"; 1889 - "É proclamada a República (15 de novembro)"; 1890 - "Congresso constituinte"; 1891 - "Constituição republicana (24 de fevereiro). Eleição do general Deodoro da Fonseca. Dissolução do Congresso (golpe de estado, 3 de novembro), revolta da armada e renúncia do Marechal Deodoro (23 de novembro). Governo do Vice-presidente Floriano Peixoto"; 1892 - "Atos de 11 de abril (deportação de generais)"; 1895 - "6 de setembro. Revolta da armada"; 1894 - "Rendição dos revoltosos no Rio (13 de março)"; 1894 - "15 de novembro. Governo do Dr. Prudente de Moraes, primeiro presidente civil (1894-98)"; 1898 - "15 de novembro. Governo do presidente Dr. Campos Salles". Os acontecimentos lembrados na cronologia são todos relacionados a guerras, a golpes, a revoltas e a governos. No caso da República, além da instauração do regime, movimento intitulado de proclamação, existe sua institucionalização, via Constituinte e Constituição; os governos, lembrando as eleições e os mandatos presidenciais; e as batalhas, fazendo referência à Revolta da Armada.

Além das gravuras e da cronologia, o livro possui também quadros sinópticos, que auxiliam na sistematização do conteúdo. A República aparece como terceiro item da sinopse geral do Segundo Reinado. 
- Desenvolvimento das ideias democráticas (a abolição, o partido e imprensa republicana, e nenhum apoio do $3^{\circ}$ reinado nas classes conservadoras).

- A questão militar. Revolução de 15 de Novembro de 1889. Os presidentes da república: Marechal Deodoro, Marechal Floriano, Dr. Prudente de Moraes e Dr. Campos Salles. (Ribeiro, 1900, p.116)

Pelo quadro sinóptico e pelo capítulo sobre a República é possível perceber a linha de interpretação apresentada por Ribeiro. A República é entendida como fruto do desenvolvimento das ideias democráticas. Logo, o regime monárquico, com tal desenvolvimento, não tinha alternativa, estava fadado a acabar, como aconteceu. A monarquia se enfraqueceu em razão de múltiplos fatores: a abolição; o movimento republicano - o partido e a imprensa -; a rejeição a um $3^{\circ}$ reinado. Fora isso, os atritos entre governo e militares - do Exército e da Armada - terminaram promovendo a derrubada da monarquia e a instauração da República, intitulada, pelo autor, de "revolução".

Na realidade, o capítulo sobre a República trata do fim do império, ou seja, termina no momento da proclamação. O que é acrescentado a mais fica circunscrito à citação dos governos presidenciais até o de Campos Salles, presidente da República em 1900, quando da publicação do livro. Além disso, o fim da escravidão é tratado dentro do capítulo da República, já que é visto como um dos fatores que possibilitaram o desenvolvimento das ideias democráticas. No capítulo, de alguma forma, é possível perceber o elenco de fatores que futuramente a historiografia terminou por consolidar como meio de explicação para o surgimento do regime republicano.

Ribeiro inicia o capítulo afirmando que o fim da Guerra do Paraguai promoveu a "expansão da riqueza pública" e "avivou o sentimento democrático". Em seguida cita a lei do ventre livre, o fundo de emancipação do cativo e a propaganda abolicionista como peças fundamentais para o fim da escravidão. Afirma que apesar de a monarquia ter ganhado a glória com a abolição da escravidão, perdeu suas bases de apoio institucional, ou seja, os senhores de escravos, membros da aristocracia. Somada à abolição, a propaganda republicana, o medo de um $3^{\circ}$ reinado e o conflito entre governo e militares promoveram a proclamação do novo regime, sem resistência. A relação entre República e espírito democrático permitiu a Ribeiro construir uma História do Brasil em que a instauração do novo regime foi entendida como revolucionária. 
O FIM DA HISTÓRIA

Por isso a História vai veloz como uma seta

Atrás do seu futuro, atrás do seu destino

José Isidoro Martins Júnior

Visões de Hoje, Recife, Typ. Industrial, 1881, p.28.

A última palavra do livro de Felisbello Freire é FIM. Terminar com a palavra FIM, em caixa-alta, aproxima a história da narrativa romanesca, reforça o fato de que é um tipo de escrita que encadeia eventos e personagens, atribuindo algum sentido ao que aconteceu. A grande diferença em relação à narrativa ficcional - do romance, por exemplo - é o compromisso da história oitocentista com o verdadeiro, "com o que realmente aconteceu", para usar a conhecida expressão de Leopold von Ranke, um marco da historiografia metódica oitocentista. Com isso desejamos destacar uma característica dos manuais escolares do período em foco, ou ao menos de alguns deles, que é buscar a aproximação com o leitor, pondo em prática recursos que supostamente possam contribuir para uma melhor aceitação dos argumentos apresentados. Num momento de tumulto e incerteza, "virtualmente avesso à narração sistemática", como observou Renato Lessa (2001, p.18), é interessante observar que os manuais escolares procuravam, justamente, estabelecer uma narrativa sistemática sobre o passado recente, o presente vivido pelos próprios autores em questão. Consideramos que a transformação da experiência, ao tornar o presente instável e produzir incertezas quanto ao futuro tornou urgente a busca de sentido por meio de releituras do passado. Os autores dos manuais escolares talvez tenham sido os mais velozes na busca de construção de um sentido para a história a ensinar.

Nos livros escolares é possível acompanhar a construção do presente como algo novo que supera e controla o tempo aberto pela nova experiência. Essa construção implicou uma revisão do passado capaz de localizar as raízes da República, de modo a demonstrar sua inevitabilidade.

\section{REFERÊNCIAS}

ABREU, Capistrano de. O Brasil no século XIX. In: Ensaios e estudos: crítica e história. Rio de Janeiro: Civilização Brasileira; Brasília: MEC, 1977. (Orig. publ. como "O Brasil no século", A Notícia, Rio de Janeiro, $1^{\circ}$ jan. 1900). 
ANDRADE, Vera Cabana de Queiroz. Colégio Pedro II: um lugar de memória. Tese (Doutorado em História) - UFRJ. Rio de Janeiro, 1999.

ARAÚJO, Valdei Lopes de. A experiência do tempo: conceitos e narrativas na formação nacional brasileira (1813-1845). São Paulo: Hucitec, 2008.

BATISTA, Antonio Augusto Gomes. Um objeto variável e instável: textos, impressos e livros didáticos. In: ABREU, Márcia (Org.) Leitura, história e história da leitura. São Paulo: Fapesp, 1999. p.529-575.

BÉDARIDA, François. L'historien régisseur du temps? Revue Historique, n.122, p.324, janv.-mars 1998.

BITTENCOURT, Circe. Os confrontos de uma disciplina escolar: da história sagrada à história profana. Revista Brasileira de História, São Paulo, v.13, n.25/26, set. 1992-ago. 1993, p.193-221.

CARVALHO, José Murilo de. A formação das almas: o imaginário da República no Brasil. São Paulo: Companhia das Letras, 1990.

CEZAR, Temístocles. A emergência do presente na escrita da história pós-1968. In: BARBOSA, Cibele (Org.) Teoria da história e historiografia: debates pós-68. Recife: Fundação Joaquim Nabuco; Ed. Massangana, 2012. p.113-132.

. Em nome do pai, mas não do patriarca. Ensaio sobre os limites da imparcialidade na obra de Varnhagen. História, São Paulo, v.24, n.2, p.207-240, 2005.

Lição sobre a escrita da história. Historiografia e nação no Brasil do século XIX. Diálogos - Revista de História da Universidade Estadual de Maringá, Maringá (PR), v.8, n.1, p.11-29, 2004a.

Presentismo, memória e poesia. Noções de escrita da história do Brasil no Oitocentos. In: PESAVENTO, Sandra Jatahy (Org.) Escrita, linguagem, objetos: leituras de história cultural. Bauru (SP): Edusc, 2004b. p.43-80.

FERREIRA, Marieta de Moraes. Demandas sociais e história do tempo presente. In: VARELLA, Flavia; MOLLO, Helena; PEREIRA, Mateus Henrique de Faria; MATA, Sergio da (Org.) Tempo presente e usos do passado. Rio de Janeiro: Ed. FGV, 2012. p.101-124.

FONSECA, Thais Nivea. Da infâmia ao altar da pátria: memória e representações da Inconfidência e de Tiradentes. Tese (Doutorado em História) - FFLCH/USP. São Paulo, 2001.

FREIRE, Felisbello. Historia do Brasil. $1^{\circ}$ Grau. Rio de Janeiro; São Paulo: Livraria Classica de Alves, 1896.

GOMES, Angela de Castro. Primeira República no Brasil: uma história da historiografia. In: ; MOURÃO, Alda (Org.) A experiência da Primeira República no Brasil e em Portugal. Rio de Janeiro: Ed. FGV, 2011. O velho vaqueano. Capistrano de 
Abreu (1853-1927): memória, historiografia e escrita de si. Rio de Janeiro: 7Letras, 2013. p.245-320.

GOUVÊA, Francisco. Proclamação e revolta: recepções da república pelos sócios do IHGB e a vida da cidade (1880-1900). Tese (Doutorado em História) - PUC-Rio. Rio de Janeiro, 2012.

GUIMARÃES, Manoel Salgado. Historiografia e nação no Brasil, 1838-1857. Rio de Janeiro: Ed. Uerj, 2011.

. Nação e civilização nos trópicos. Estudos Históricos, Rio de Janeiro, n.1, p.527, 1988.

HALLEWEL, Laurence. O livro no Brasil: sua história. São Paulo: T. A. Queiroz; Edusp, 1985.

HANSEN, Patrícia Santos. Feições e fisionomia: a história do Brasil de João Ribeiro. Rio de Janeiro: Access, 2000.

HARTOG, François. O olhar de Tucídides e a história "verdadeira". In: Evidência da história: o que os historiadores veem. Belo Horizonte: Autêntica, 2011. p.77-91.

LACERDA, Joaquim Maria de. Pequena história do Brazil por perguntas e respostas para uso da infância brasileira. Rio de Janeiro: Livr. Francisco Alves, 1919.

LESSA, Renato. A invenção da República: da aventura à rotina. In: CARVALHO, Maria Alice Rezende de (Org.) A República no Catete. Rio de Janeiro: Museu da República, 2001.

MAGALHÃES, Gonçalves de. Observações preliminares. RIHGB, tomo X, 1848.

MELLO, Maria Tereza Chaves de. A modernidade republicana. Tempo - Revista de História, Niterói (RJ), n.26, p.15-31, 2009.

A república consentida: cultura democrática e científica do final do Império. Rio de Janeiro: Ed. FGV, 2007.

RIBEIRO, João. Historia do Brasil. Adaptada ao ensino primario e secundario por João Ribeiro. Professor de Historia da Civilização e Historia do Brasil do Gymnasio Nacional. Rio de Janeiro: Livr. Cruz Coutinho, 1900. 1901.

Historia do Brasil. Curso superior. 2.ed. Rio de Janeiro: Livr. Francisco Alves,

Historia do Brasil. Edição das escolas primárias. 2.ed, com estampas. Rio de Janeiro; São Paulo; Belo Horizonte: Livr. Francisco Alves, 1900.

RODRIGUES, José Honório. A periodização na história do Brasil. In: Teoria da história do Brasil: introdução metodológica. 1.ed. 1949. São Paulo: Cia. Ed. Nacional, 1978. p.124-144.

TIBURSKI, Eliete Lucia. Escrita da história e tempo presente no Brasil oitocentista. Dissertação (Mestrado em História) - UFRGS. Porto Alegre, 2011. 


\section{NOTAS}

${ }^{1} \mathrm{O}$ interesse da historiografia pelo tempo presente manifesta-se, por exemplo, na criação de instituições dedicadas à pesquisa e à guarda de documentação relevante para sua compreensão, como o Centro de Documentação de História Contemporânea do Brasil (CPDOC), da Fundação Getulio Vargas, no Rio de Janeiro, criado em 1973, e o Instituto de História do Tempo Presente, fundado em Paris, no ano de 1978. Também se manifesta por meio do desenvolvimento da história oral e dos estudos sobre a memória social. A esse respeito, ver: CEZAR, 2012; FERREIRA, 2012.

${ }^{2}$ Sobre a relação dos historiadores antigos com o presente, ver: HARTOG, 2011.

${ }^{3}$ Sobre a questão do presente na historiografia brasileira oitocentista, ver: CEZAR, 2005; 2004b; TIBURSKI, 2011.

${ }^{4}$ Utilizamos a expressão usos do presente inspirados pela obra organizada por François Hartog e Jacques Revel, Usages politique du passé. A expressão traduz uma prática ou ação no sentido de apreender o tempo - no caso, o presente, considerando a definição de que esse tempo corresponde ao período cujos testemunhos estão vivos - transformando-o em objeto de análise sujeito a múltiplos usos sociais e políticos. Sobretudo se considerarmos o historiador como um 'registrador do tempo': alguém que inscreve o passado no presente estabelecendo um ponto em direção ao futuro e legitimando uma releitura das fontes em busca de sentido, como propôs François Bédarida (1998).

${ }^{5}$ Ver GOUVÊA, 2012, p.31 e 125. O autor utiliza a noção de moldura: esperiências passadas que permitem enquadrar a república na ordem do tempo. No caso, destaca duas: o período regencial e a independência.

${ }^{6}$ Sobre a espera de uma nova história do Brasil, ver: GONTIJO, 2013.

${ }^{7}$ Sobre a escrita da história no Brasil do século XIX, ver: GUIMARÃES, 1988; CEZAR, 2004a.

${ }^{8}$ A percepção de viver em uma época de transição, sujeita a instabilidades capazes de abalar a crença no futuro, estava presente em meados do século XIX como, por exemplo, em MAGALHÃES, 1848, p.263. De acordo com Eliete Tiburski, os escritos de Gonçalves de Magalhães representaram uma tentativa bem-sucedida de história do tempo presente, num contexto em que projetos desse tipo eram frequentemente vetados. Ver ibidem, p.88. Ver também: ARAÚJO, 2008, e GUIMARÃES, 2011.

${ }^{9}$ Um exemplo é a permanência do livro Lições de história do Brasil, de Joaquim Manoel de Macedo. Publicado pela primeira vez em 1861, foi revisto e atualizado por Olavo Bilac em 1905, e por Rocha Pombo em 1922. A estrutura do livro - e, consequentemente, as ideias do autor monarquista - permanece a mesma, e os revisores, ambos republicanos, apenas acrescentam novas lições visando aproximação com o presente. Atualizar parece ser sinônimo de ampliar conteúdos. Outro exemplo é o livro Pequena história do Brazil por perguntas e respostas para uso da infância brasileira [1898]. O autor é Joaquim Maria de Lacerda, e a obra tem edição revista e aumentada por Luiz Leopoldo Fernandes Pinheiro em 
1906. No prólogo dessa edição, Pinheiro afirma que a primeira edição da obra por ele revista esgotou-se rapidamente, como prova evidente da aceitação que recebeu do público, "não só pela conservação do método do autor, como pelos melhoramentos e acréscimos nela introduzidos". Ver LACERDA, 1919. A última edição do livro localizada é de 1957.

${ }^{10}$ Há pelo menos dois estudos importantes sobre a construção de Tiradentes como herói republicano: CARVALHO, 1990, e FONSECA, 2001.

${ }^{11}$ O Colégio Pedro II foi fundado em 1837, renomeado na República, em 1891. Ver: ANDRADE, 1999.

${ }^{12}$ Só como um exemplo do peso do processo de emancipação no interior do último capítulo do livro, consideramos importante lembrar uma característica da diagramação presente na edição Historia do Brasil. Adaptada ao ensino primario e secundario por João Ribeiro, publicada em 1900, pela Livraria Cruz Coutinho. Como recurso de diagramação, as páginas do livro traziam no cabeçalho referência aos títulos dos capítulos. No caso do oitavo capítulo, onde o teor do texto era idêntico ao da segunda edição do Curso Superior, o cabeçalho se referia apenas à abolição e não à república. Ver: RIBEIRO, 1900.

${ }^{13}$ É interessante contrastar a interpretação de João Ribeiro sobre o processo da abolição com aquela apresentada por Capistrano de Abreu, no artigo O Brasil no século, publicado em 1900. Artigo que chama atenção por ser um raro escrito sobre a história do presente elaborado por um historiador que se destacava por estudar os séculos XVI e XVII. Sobre a questão da abolição, Capistrano, após rever as mudanças na legislação sobre a escravidão, defende que a entrada em cena dos escravos "por êxodos consideráveis das fazendas", determinou o fim do cativeiro. Ou seja, a eficácia da ação dos escravos aboliu a escravidão "sem resistência" e "ano e meio depois caía a monarquia". Ver ABREU, 1977, p.96.

Artigo recebido em setembro de 2013. Aprovado em outubro de 2013. 